Fecha de recepción: abril 2020 Fecha de aceptación: mayo 2020 Versión final: junio 2020

\section{Encuentros y desencuentros en el dise- ño e implementación de un Programa de Educación Intercultural Bilingüe en la provincia del Neuquén, Argentina. Una mirada antropológica}

Andrea Szulc ${ }^{(1)}$

\begin{abstract}
Resumen: La provincia del Neuquén se ha caracterizado históricamente por una fuerte presencia estatal en las comunidades mapuche, fundamentalmente a través del establecimiento de escuelas primarias y postas sanitarias. En tales escuelas, se interpela fuertemente a los niños y niñas desde la definición identitaria hegemónica -que articula las pertenencias provincial, nacional y católica, subordinando a ellas la identidad mapuche- y desde un modelo escolar de niñez. La investigación antropológica realizada allí desde el año 2001, evidencia también cómo algunos niños, niñas, adolescentes y adultos/as mapuche vienen cuestionando abiertamente tales concepciones.

El presente artículo explora entonces -tras una breve descripción del sistema educativo provincial- los encuentros y desencuentro en el diseño e implementación de un Programa Provincial de Enseñanza de Lengua y Cultura Mapuche en este contexto, analizando los lineamientos de esta política provincial y las perspectivas y prácticas de los actores institucionales, comunitarios, familiares y de los propios niños y niñas. A partir principalmente de materiales etnográficos originales, el análisis revela cómo en el tiempo transcurrido desde la puesta en marcha del Programa en el año 2001, nuevas generaciones de jóvenes maestros y maestras mapuche se han ido posicionando de otro modo, promoviendo espacios vivenciales de autoreconocimiento, en lugar de la presentación descontextualizada, fosilizada y despolitizada de la lengua y la cultura mapuche que registramos en sus primeros años (Szulc 2009)
\end{abstract}

Palabras clave: Diseño de política indigenista - niñez - identidad mapuche - trayectorias escolares.

[Resúmenes en inglés y portugués en las páginas 136 - 137]

(1) Licenciada y Doctora en Ciencias Antropológicas por la Facultad de Filosofía y Letras, Universidad de Buenos Aires. Investigadora Independiente del Consejo Nacional de Investigaciones Científicas y Técnicas. Docente de grado y posgrado en la Universidad de Buenos Aires, en las áreas de antropología con pueblos indígenas y antropología de las infancias. Directora del equipo Niñez Plural. 


\section{Introducción}

Al terminar la jornada escolar los chicos se formaron en filas, ordenados por grado, cerca del mástil donde flameaban la bandera argentina y, abajo, la neuquina. Una de las maestras, dada la ausencia de la directora, eligió a los escoltas del día. Una chica de 7 mo grado dijo que no y uno de sus compañeros protestó “¡no se puede negar a la bandera, maestra!”. Entonces la maestra le preguntó a la chica por qué se negaba, y ella respondió que "para dejar lugar a otros, porque yo paso muy seguido". La maestra aceptó la respuesta y la repitió en voz más alta y con entonación aleccionadora. Bajaron las dos banderas en silencio, las desataron del mástil y las llevaron a la dirección. El resto de los chicos siguió de pie formados en filas. Luego, los docentes, uno a uno, fueron saludando al conjunto de alumnos "Hasta mañana chicos!", y -"a coro" y con la tradicional entonación escolar, separando y acentuado cada sílaba- ellos respondieron: “Has-ta-ma-ña-na ma-es-tra!". La última en saludar fue la maestra mapuche: 'Ka pewkajael picikece'. Con idéntico estilo y desgano se hizo oír la respuesta: "Ka-pew-ka-jael kv-mel-tu-fe!" (Dto. Huiliches, febrero de 2004) ${ }^{1}$.

El actual programa de enseñanza de lengua y cultura mapuche de la provincia del Neuquén (PELCM) se propuso en el año 2000 como antítesis de la política educativa históricamente hegemónica en la Argentina, que ha interpelado a los niños indígenas según un modelo de nación monocultural y europeizante. ${ }^{2}$ Sin embargo, como en parte anticipa la situación etnográfica descrita, el análisis de su implementación revela más que acciones tendientes a la enunciada "preservación de la cultura indígena", redoblados esfuerzos por hacer de los niños y niñas mapuche leales neuquinos, argentinos y buenos cristianos.

En esta oportunidad, argumentaré por un lado que durante mucho tiempo esto se concretó mediante la restricción del PELCM a determinadas comunidades mapuche rurales -aquellas reconocidas formalmente por el estado provincial-, la subordinación del mapuzugun a la lengua castellana, la fosilización de los elementos culturales mapuche y su reducción a la lógica escolar. Por otro lado, plantearé que en los últimos años una nueva generación de jóvenes maestros y maestras mapuche se han ido posicionando de otro modo, promoviendo espacios vivenciales de autoreconocimiento, en lugar de la presentación descontextualizada y fosilizada de la lengua y la cultura mapuche que registramos en los primeros años del PELCM (Szulc, 2009), logrando incluso la designación de una maestra mapuche en la ciudad capital de la provincia.

A partir de una conceptualización de la niñez como campo de disputas por la hegemonía (Williams, 1997) y de los niños y niñas como sujetos sociales e interlocutores competentes, exploraré aquí los diferentes sentidos de pertenencia (Brow, 1990) promovidos por este programa educativo en diferentes momentos y las perspectivas de los niños y niñas al respecto. Analizaremos para ello -junto con documentación oficial y fuentes periodísticas- materiales etnográficos originales, relevados entre el año 2001 y 2019 en la zona centro y sur de la provincia del Neuquén en contextos rurales y urbanos. ${ }^{3}$ Tras una breve descripción del sistema educativo regional, el análisis presenta aspectos centrales del diseño e implementación 
del PELCM, que mayormente ha procurado transmitir a los niños y niñas un particular y hegemónico sentido de pertenencia en el cual confluyen lo argentino, lo neuquino, lo católico y una definición despolitizada y subordinada de lo mapuche. En esta oportunidad analizaremos también las diversas respuestas de la población mapuche a este programa y a las identificaciones étnica, nacional y provincial que promueve. Así, podremos comprender mejor cómo en los últimos años han ido surgiendo nuevas prácticas que apuntan a construir diversamente estas posiciones subjetivas (Hall, 1986; Mouffe, 1988).

\section{Sobre el sistema educativo y el diseño del programa de Educación Intercul- tural Bilingüe en el Neuquén}

La escuela en la Argentina ha tenido un rol central en la conformación de las nuevas generaciones, según un modelo de nación "blanca" y cuasi europea, que, para los pueblos originarios ha significado la negación y estigmatización de la propia identidad y la prohibición -explícita o implícita- de sus prácticas socioculturales y lingüísticas (Hecht y Szulc, 2006). El argumento nacional operó como fuente de legitimación de los fines educativos, e incluso del propio estado desde los inicios del sistema de instrucción pública (Puiggrós, 1990, p. 45). En el caso neuquino, el sistema educativo ha jugado asimismo un rol clave en la construcción de las identidades nacional y provincial, predominando las políticas asimilacionistas desde la etapa en que fue Territorio Nacional, iniciada en 1884 (Sánchez, 2004; Teobaldo, 2000), quedando la escuela y los/as docentes marcados a largo plazo por el mandato de "integrar a la población indígena" (Díaz, 2001, p. 40), tras la "Conquista del Desierto". No obstante, en la práctica el período territoriano se caracterizó por una débil estructuración del campo educativo (Teobaldo, 2000) y de la institucionalidad estatal en general. Así, durante la primera mitad del siglo XX, para la mayor parte de la población mapuche -tanto si accedieron a internados salesianos o estatales como si asistieron a establecimientos públicos en los centros poblados- el paso por la escuela fue fugaz, apenas algunos meses o un par de años del nivel primario.

A partir de la provincialización del Neuquén en 1958, la educación pasó a ser una línea clave de política estatal, pues el gobierno provincial -encabezado ininterrumpidamente desde 1962 por el Movimiento Popular Neuquino (MPN)- centró su accionar en las mejoras en infraestructura y el fortalecimiento de los sistemas educativo y sanitario. Así, en general las condiciones edilicias de estas escuelas son buenas, comparadas con las escuelas rurales de otras provincias. Sin embargo, en cuanto a calidad educativa, el propio sistema educativo provincial desvaloriza en la práctica la educación allí impartida; por ejemplo exigiendo a los niños que, habiendo egresado de allí, procuran ingresar a establecimientos de educación media (urbanos, pues rurales casi no hay), que previamente "repasen" en la ciudad uno o dos años de la escuela primaria. Así, tal como señala Rockwell:

Las diferencias culturales que existen (...) no afectan la capacidad de aprendizaje en 'abstracto', pero sí interactúan con la escuela en formas concretas. Sobre 
todo, provocan de la escuela, como institución, no una actuación neutral, sino una marcada diferenciación en su trato a los alumnos (...) (1980, p. 6-7).

No obstante, las mejoras en infraestructura y cobertura de los sistemas educativo y sanitario han contribuido sustancialmente al proceso de comunalización (Brow, 1990) en torno a "lo neuquino". Tal sentido de pertenencia provincial se ha caracterizado por una manifiesta confrontación con el estado nacional y una incorporación simbólica de lo mapuche como "una de las figuras emblemáticas de lo local" (Mombello, 2005, p. 174), según un modelo de pluralismo basado en la subordinación tolerante, que aún reconociendo en cierta medida la heterogeneidad avala "lo deseable e inevitable de la homogeneización en el largo plazo" (Briones, 2004, p. 123).

La política provincial de regularización de las comunidades mapuche -por la cual se adjudicaron en 1964 tierras en carácter de "reserva" a dieciocho "agrupaciones"- previó un espacio para la escuela, encargada de impartir a los niños una educación común (Sánchez, 2004), y otros edificios públicos, exigiendo a la población mapuche beneficiaria la escolarización de sus hijos (Briones, 1999). En estos contextos la escuela continúa en la actualidad desempeñando un papel central, "a veces, como único enclave estatal" mediante el cual se introducen otras iniciativas sanitarias, asistenciales (Díaz, 2001, p. 50) y religiosas.

Es en algunas de estas escuelas que al comenzar este siglo XXI se ha puesto en marcha un programa de Educación Intercultural Bilingüe (EIB), a partir de un modelo educativo presentado como abierto a la diversidad étnica y lingüística que fue ganando consenso a nivel nacional e internacional (López, 2006), y en confluencia con el reconocimiento de los derechos de los pueblos indígenas. ${ }^{4}$ No obstante, en esta área se observan avances desiguales entre las diferentes provincias (Hecht 2015) ${ }^{5}$, a la vez que sobresalen, por un lado, la muy escasa capacitación del personal docente sobre la educación intercultural y los temas indígenas, al igual que las persistentes barreras a la participación indígena. El área además ha registrado avances, retrocesos y cambios de rumbo al compás de los vaivenes políticos nacionales. ${ }^{6}$

No obstante, en tanto las escuelas son gestionadas por cada una de las provincias desde la sanción de la Ley Federal de Educación en 1993, corresponde aquí que atendamos al contexto neuquino específicamente, donde además las iniciativas de EIB antecedieron a la creación de la Modalidad de EIB en el ministerio de educación nacional y son definidas y gestionadas a nivel provincial.

El actual Programa de Enseñanza de Lengua y Cultura Mapuche de la provincia del Neuquén (PELCM) fue implementado en escuelas primarias de comunidades rurales a mediados del año 2000, aunque se basa en resoluciones y acciones iniciadas en 1995. A diferencia de otras provincias argentinas donde la EIB deriva de una ley integral sobre pueblos indígenas, en Neuquén se ha generado mediante resoluciones del Consejo Provincial de Educación y decretos del Poder Ejecutivo, normativa de inferior alcance y jerarquía jurídica (Szulc, 2009). La resolución inaugural fundamentó el PELCM en "la necesidad de las comunidades indígenas de preservar su lengua y su cultura" y en la responsabilidad del estado y de la institución educativa de "velar por la preservación de la cultura indígena", privilegiando la lengua como "vehículo de expresión de la cultura". 
Formalmente el PELCM consiste en la incorporación "con carácter optativo" de "la enseñanza de lengua y cultura mapuche en escuelas primarias insertas en agrupaciones indígenas", con una carga horaria de diez horas semanales para cada maestro/a. De éstas, seis horas se distribuyen entre las secciones de cada escuela, y las cuatro restantes deben destinarse al trabajo de "rescate cultural" con la comunidad. En 1995 se creó el cargo de maestro especial de lengua mapuche, se definió su carga horaria y su retribución, asignando su elección y seguimiento a la comunidad y a la dirección de cada escuela en conjunto. Si bien no se requirió a los candidatos título habilitante, ya que no existen en Neuquén profesorados con esta orientación, en la práctica se demandó "saber leer y escribir". De ese modo fueron designados y comenzaron a trabajar algunos maestros/as mapuche, que se desempeñaron sólo durante 1996, luego de lo cual el cargo fue "desactivado" (Díaz, 2001).

En el año 2000 el PELCM fue retomado, en gran medida como medio para contener las demandas de interculturalidad que por ese entonces cobraban consenso en la sociedad civil, articuladas en esa coyuntura en torno al proyecto de la Coordinadora de Organizaciones Mapuche (COM, 2000). No obstante, argumentando vincularse directamente con las comunidades, el poder ejecutivo local no sometió el PELCM al debate con las organizaciones mapuche que las nuclean (Briones, 2004), al tiempo que obstaculizó la financiación de sus proyectos por parte del Ministerio de Cultura y Educación de la Nación (Lanusse, 2004).

Al reeditarse el programa, se lo ubicó bajo la órbita de un nuevo organismo, la Dirección de Programas Educativos e Idioma Mapuche (DPEIM), a cargo de un funcionario mapuche. En este nuevo diseño, la DPEIM pasó a concentrar las pequeñas decisiones y la información, interviniendo en la selección, capacitación, evaluación de los maestros/as y la renovación anual de sus cargos. Como describió un colaborador de esa dirección "los nombramientos salen de la mano del Director". Así, el cargo devino en muchos casos un beneficio más a distribuir discrecionalmente según mecanismos clientelísticos, equivalente en su monto y precariedad al subsidio mínimo para jefes de hogar desocupados.

El relanzamiento del año 2000 -ampliamente cubierto por la prensa local- introdujo en la normativa un vocabulario más políticamente correcto que, por ejemplo, reemplazó "cultura indígena" por "cultura de los pueblos Originarios" y sumó el fin de "mejorar la calidad de vida de la población, en un marco de igualdad de oportunidades y posibilidades". Me detendré a continuación a analizar cómo se realiza este programa en la práctica.

\section{Análisis del programa en la práctica}

Más allá del diseño enunciado en la documentación oficial, es imprescindible atender a las experiencias escolares cotidianas en el marco del PELCM, pues comunican interpretaciones sobre la realidad y orientaciones valorativas no necesariamente explícitas en los programas oficiales (Rockwell, 1995). Abordaré aquí las prácticas observadas en los establecimientos educativos, conjuntamente con las experiencias y nociones expresadas por directivos/as y docentes no indígenas y por la población mapuche - maestros/as, funcionarios/as, miembros de organizaciones, padres, madres y alumnos/as- priorizando las perspectivas de los 
propios niños y niñas involucrados. El análisis se ordena en función de interrogantes acerca de dónde, qué y cómo se enseña, cómo ha sido recibido por los niños y niñas mapuche y sus madres y padres, y cómo se define de distintos modos la identidad mapuche, aun cuando -como se verá- son aspectos íntimamente relacionados entre sí.

\section{¿Dónde se enseña lengua y cultura mapuche?}

En el PELCM la EIB se planteó como política focalizada, destinada sólo a escuelas insertas en comunidades mapuche, las cuales materializan en el área rural neuquina la presencia efectiva del estado. Las escuelas rurales de comunidad son entre pequeñas y medianas. En los casos analizados contaban con entre dos y cuatro secciones para el funcionamiento de los siete grados, con un/a docente por sección, totalizando de 28 a 65 alumnos. En estos y otros casos es extremadamente reducida la posibilidad de las familias de elegir otro establecimiento para sus hijos e hijas, pues no disponen de medios para el traslado diario a otro paraje. Así, la población indígena deviene una suerte de "público cautivo" de la institución, dependiendo la experiencia escolar de estos niños y niñas de la buena voluntad y capacidad de "la directora de turno".

El nivel de instrucción y el trato que reciben los niños y niñas por parte del personal docente no mapuche suele detonar la conflictividad que históricamente caracteriza la presencia estatal en estos contextos. Son frecuentes las denuncias de descompromiso, negligencia e incumplimiento del horario escolar de los/as docentes, casi sin excepción no mapuche y, en los casos estudiados, residentes en las ciudades cercanas. ${ }^{7}$

En este campo conflictivo, la incorporación del proyecto provincial de EIB ha generado otro tipo de tensiones entre la escuela, las comunidades y organizaciones indígenas, que advierten en la circunscripción del programa a las comunidades rurales un subyacente anhelo de "integración", en sentido asimilacionista; en tanto “(...) la idea de integración en estos casos suele usarse para señalar el movimiento que 'ellos' deben hacer hacia 'nosotros' (...) Estos discursos parten de un supuesto: el que tiene que integrarse siempre es el aborigen, el otro, el diferente" (Novaro, 2004: 490). El movimiento en sentido contrario, que implicaría que los niños no-indígenas se tornen bilingües, no parece siquiera concebible. Los niños/as y adultos/as mapuche -tanto de la ciudad como del campo- están al tanto de que "las clases de mapuche" se han impartido hasta 2017 sólo en zonas rurales. A muchos de ellos no les resultaba extraño, pues tal recorte es compatible con la idea -instalada fuertemente en el sentido común- de que quien ha migrado a la ciudad deja de ser mapuche (Szulc, 2004).

Sin embargo, considerando el peso demográfico y político-cultural de la población urbana, la prolongada circunscripción de este emprendimiento educativo al ámbito rural, y a su vez a aquellas comunidades rurales reconocidas por el estado provincial, constituye un interesante indicio del modo en que se definía la identidad mapuche en el diseño de este programa. 


\section{¿Qué y cómo se enseña en el PELCM?}

Después de saludar en castellano y en mapuzugun la maestra mapuche extrajo de una pequeña bolsa plástica un ramo de hojas con su vaina. Abrió la vaina y extrayendo arvejas preguntó en castellano “¿Qué es esto?”. Varios chicos a la vez respondieron “arvejas!" “Se come esto, no?”. Mostrando ahora las hojas indagó: “¿Y cómo se decía esto en mapuche?”. Luego de unos segundos de silencio la maestra sugirió la respuesta “Ta..., y entonces Jonathan completó “Tapl”. "Muy bien!", lo felicitó la maestra. A continuación entregó a cada niño un papel en el cual bajo el nombre del niño estaba escrito "Tap'l alfish - hoja de arveja”. Distribuyó además una hoja y trozos de cinta adhesiva. Fue aproximándose a cada niño, ayudándolos a pegar la hoja bajo el texto escrito (Clase con niños de 5 años, Huiliches, Febrero de 2004).

Como se advierte en el ejemplo presentado, los/as maestros/as mapuche trabajan como maestros especiales, haciéndose cargo de cada sección durante un período determinado (por lo general una o dos horas cátedra semanales), e impartiendo su clase al grupo en su conjunto, incluyendo a niños y niñas mapuche y unos pocos no mapuche. El PELCM constituye entonces una asignatura y no un programa de inmersión lingüística, cuya pertinencia está dada por el contexto, al dictarse en escuelas situadas en comunidades mapuche.

La situación presentada también indica que el idioma mapuche ocupa en la práctica de esta asignatura, al igual que en su diseño, un lugar central, aunque subordinado al castellano. Como puede apreciarse, el mapuzugun no es utilizado para interactuar con los alumnos, sino que se procura la incorporación de vocabulario en esa lengua. La dinámica ejemplificada suele repetirse en los otros grupos escolares.

Esta y otras observaciones realizadas indican que en términos generales, luego del saludo inicial en mapuzugun, el/la docente pasa al castellano cuando formula preguntas, explica, propone consignas, aprueba o corrige una respuesta e incluso cuando nombra la lengua indígena como "mapuche" en lugar de como mapuzugun. Por ello planteo aquí que en el PELCM el castellano -lengua utilizada desmarcadamente para la comunicación- subordina al mapuzugun, que se utiliza sólo como lengua objeto de enseñanza o "target" language.

Por otra parte, nuestro ejemplo también permite entrever el hincapié en la escritura que ha hecho el PELCM desde sus comienzos. Aunque orientada a jerarquizar la lengua mapuche en el ámbito escolar, resulta relevante señalar que la escritura en estos contextos no fue demandada por la población mapuche atendida por esta política, sino pautada por la DPEIM. Si bien la instauración de lo escrito fue difícil al comienzo "porque los futuros maestros se resistían a la escritura, al pizarrón”, según manifestó personal de la DPEIM, la capacitación dio sus frutos, observándose en la práctica cotidiana la asignación de un rol central a la escritura por parte de los/as docentes. Por ejemplo, al iniciar cada clase los maestros/ as mapuche escriben sobre el pizarrón la fecha pautada por el calendario gregoriano en mapuzugun y los/as alumnos/as la trascriben en sus cuadernos, modo habitual de iniciar la 
jornada escolar en la educación primaria en la Argentina. A pesar de que en ocasiones se seleccione y transcriba léxico ligado a la cotidianeidad de los niños y niñas, como en el caso de las hojas de arveja, la escritura se aplica con mayor frecuencia a una selección temática típicamente escolar, los números, los colores, las partes del cuerpo. Como señaló Facundo (10 años), alumno de 3er grado, "me enseña cómo se llama la mano, así, todo eso. La nariz se llama yu y acá (la oreja) se llama pilun. Y acá la cabeza, logko".

Los niños y niñas que cursan la asignatura manifestaron unánimemente la centralidad conferida a la escritura: "ella escribe, escribe, escribe y nunca nos explica nada (...). Lo único que hacemos es copiar" (Valeria, 14 años). La escritura aparece ante ellos como un fin en sí mismo, y esa es una de las causas a las cuales los niños, niñas y sus padres atribuyen la ineficacia del programa, como veremos más adelante.

La lengua mapuche entonces, además de quedar encuadrada por el castellano y no promoverse como lengua de comunicación (Meek y Messing 2007), se reduce en la práctica a saludos formales y a la escritura, por lo cual podemos afirmar que su incorporación es en gran medida superficial. La escritura se limita a lo que escolarmente se define como relevante y a un sistema ortográfico que -como veremos a continuación- castellaniza la lengua mapuche. Pues en el PELCM se utiliza una estandarización de la grafía del mapuzugun -elaborada a tal efecto por la DPEIM- cuya castellanización se alega simplificaría a los niños y niñas el aprendizaje de la lectoescritura en esta lengua, propuesta cuyos antecedentes se remontan a 1990 (Briones, 1999). Al mismo tiempo, la DPEIM rechaza el sistema consensuado por numerosas organizaciones mapuche, el grafemario Ragileo, "un subversivo sistema de escritura" (Golluscio, 2002, p.162) "que utiliza el alfabeto hispano pero reasigna sus correspondencias fonéticas para evitar castellanizar la pronunciación además de la escritura" (Briones, 2004, p.124). El argumento esgrimido para tal rechazo por funcionarios y parte de los maestros/as mapuche entrevistados es su origen "chileno", derivado de la nacionalidad de su autor. Tengamos en cuenta que el "problema chileno" -país limítrofe al que se le atribuye ambición sobre la región pampeano-patagónica argentina- ha constituido históricamente el argumento central para la implementación y el ejercicio de la soberanía argentina en zonas de frontera, y la "justificación identitaria neuquina para la provincialización del 'desierto"' (Briones y Díaz, 2000, p.45). El rechazo del grafemario Ragileo en estos términos da cuenta del modo en que el PELCM define la membresía mapuche, subsumiéndola en las identidades nacional y provincial, e impugnando la identidad transnacional. Dado que las lenguas indígenas no constituyen sólo un instrumento de comunicación sino también el locus en y a través del cual se recrean identidades (Sherzer, 1981), estas disputas en torno a la elección del sistema ortográfico lejos de reducirse al nivel de la lengua, comportan "significado político y social" (Golluscio, 2002, p.160), en tanto definen la pertenencia mapuche en sentidos divergentes.

Con respecto a la cultura mapuche, la puesta en práctica del PELCM ha revelado que habitualmente se presentan a los alumnos elementos aislados como "las plantas medicinales", "las leyendas mapuche", en castellano, dedicándole menos tiempo que a la enseñanza del mapuzugun. Al igual que ocurre con la lengua, la cultura mapuche se ve reducida a la "lógica escolar", que implica un fuerte énfasis en la escritura y la descontextualización de las palabras e ideas presentadas por el docente (Chiodi, 1997). 
Dicha descontextualización concuerda con la explícita orientación del PELCM hacia la "preservación de la cultura", lo cual implica una selección de contenidos tomados del pasado, y del ámbito simbólico únicamente, que resaltan la alteridad y su recreación en la escuela desvinculados de las condiciones de vida y trayectoria histórica de esta población, de acuerdo con una visión restringida y esencialista de la cultura que configura un particular uso escolar de la cultura indígena, advertido ya en otros contextos en que se ensayan programas de EIB (Franzé, 2008; Hecht, 2004; Hermes, 2005).

Esta selección de contenidos y el modo en que se desenvuelven en el PELCM son señalados por la propia población mapuche como determinantes de los resultados obtenidos, como se verá a continuación.

\section{Respuestas mapuche ante el PELCM}

No es mi cometido establecer objetivamente si y en qué medida los niños y niñas han incorporado los contenidos presentados por los y las docentes mapuche; pues al igual que Rockwell y Ezpeleta (1985) no apunto a la dimensión interna, de aprendizaje individual, de la apropiación, a pesar de reconocer que forma parte constitutiva de los hechos observados. No obstante, resulta significativo que la mayor parte de los niños y niñas -al igual que sus padres, madres, maestros/as mapuche y no mapuche- señalan que no han aprendido mapuzugun ni avanzado en la "preservación de su cultura" como resultado de este programa, a pesar de que existen interpretaciones y valoraciones divergentes entre la población mapuche respecto del PELCM.

En primer lugar, parte de la población mapuche ha valorado este emprendimiento educativo como un reconocimiento, un "logro" y una oportunidad para que la escuela consiga lo que numerosos adultos/as mapuche no pudieron o no intentaron en su momento, enseñarles mapuzugun a sus hijos, "rescatar la cultura, la lengua, las costumbres, las creencias". Por su parte, numerosos familiares objetaron que el ámbito de aprendizaje de la lengua y cultura mapuche sea la escuela, a cuyos métodos en parte atribuyeron el escaso éxito del PELCM. Plantearon una cierta incompatibilidad entre la "lógica escolar" y el tipo de aprendizaje contextualizado habitual en el marco doméstico y comunitario, el cual "se realiza en contextos reales, en situaciones cotidianas que tienen significado y valor para el niño y para su vida en comunidad" (Hecht, 2004, p.4), que constituye "un proceso de conocimiento a través de la observación y la participación periférica y creciente" (Padawer y Enriz, 2009, p.327). Como señaló Sergio, padre de cuatro niños: "A mí me parece que así no aprende porque escriben nomás, y no aprenden a hablar, a pronunciar bien, sólo escribiendo. Antes el idioma se aprendía escuchando y hablándolo en la casa”. Han en cambio demandado la eficaz enseñanza de los saberes escolares tradicionales, asociados al ascenso social, recordándonos que en América Latina "el derecho a la educación ha sido una reivindicación popular y no simplemente un arma en manos de los sectores dominantes" (Batallán y Neufeld, 1988, p.2). Así, el caso aquí analizado nos permite indagar en las tensas interacciones entre el sistema educativo estatal y la forma mapuche de formar a los niños y niñas (Szulc, 2011). 
Dado que el PELCM ya está en marcha, los integrantes de las comunidades coincidieron en reclamar que logre un manejo competente del mapuzugun por parte de los niños como herramienta comunicativa, que les posibilite conversar con sus mayores y participar activamente en las ceremonias comunitarias, en las cuales es imperativo hablar en mapuzugun. Concuerdan así con lo demandado por otros pueblos indígenas (Godenzzi, 1997), y con la relevancia crucial conferida al uso de la lengua en la transmisión intergeneracional, en el ámbito doméstico y comunitario, para su mantenimiento (Fishman, 1991).

En segundo lugar, resulta relevante atender a los numerosos indicios de que -a pesar de haberse ajustado a la "lógica escolar"- esta asignatura no se ha incorporado acabadamente al currículum ni al funcionamiento habitual del sistema educativo. Coincidiendo con parte de la población mapuche, que arguyó la falta de supervisión del trabajo de estos maestros/as por parte de la DPEIM como causa de su escaso éxito, Isabel, directora no mapuche, explicó: "la escuela no tiene injerencia, sólo asesora al personal, junto con la Dirección de Idioma y Cultura Mapuche. Pero los han dejado muy solos [a los docentes mapuche]". A su vez, los niños y niñas informaron que la asignatura recién en el año 2004 fue incluida en el boletín de calificaciones, "pero todavía no escribieron nada" (Facundo, 10 años). La equiparación con los contenidos escolares tradicionales no parece concretarse en la práctica, sin que se hayan planteado formas alternativas de aprendizaje y evaluación. En ese mismo sentido, algunos/as docentes y directivos/as no mapuche señalaron la falta de capacitación docente de los maestros/as mapuche. Isabel, por ejemplo, planteó que "no cualquiera es docente. Le cuesta mantener el orden. Aunque ellos tienen su pedagogía, no es igual. Un docente tiene que saber didáctica y cómo poner pautas. Pero no es fácil”. Teniendo en cuenta el histórico énfasis disciplinador y normalizador que ha marcado la formación docente en la Argentina (Davini, 1995), estas expresiones deben leerse como una abierta negación de la condición "docente" de estos maestros y maestras mapuche, que se suma a la precariedad y pobre retribución de sus cargos. Dadas estas condiciones, resulta pertinente no dar por sentado que la escritura en mapuzugun aportará al mantenimiento de la lengua, en tanto no conlleva un empoderamento de los individuos que la adquieran (Hornberger, 1995).

En tercer lugar, tal desprestigio de los maestros y maestras mapuche puede haber contribuido al desinterés de los niños y niñas, consensuado como factor explicativo de los pobres resultados, incluso entre los propios niños: "porque no le hacen caso a la maestra mapuche (se ríe); no le hacemos caso" (Valeria, 14 años). Algunos padres lo atribuyen a la "lógica escolar"; los chicos se interesarían por aprender "la historia, a hablar, a responder el saludo a un abuelo".

Para algunos/as docentes mapuche la falta de interés y el bajo desempeño de los niños es resultado del rechazo - pasado o presente- de sus padres, debido al histórico accionar del sistema educativo, como sugirió Rosa:

Los chicos no le dan importancia por la educación que les dan en la casa. Tienen la lengua dura, porque ya están acostumbrados en castellano, porque los padres dejaron de enseñar por vergüenza (...) porque cuando hablaban mapu- 
che los maestros decían 'Ud. está hablando mal!' Porque costaba pronunciar el castellano, igual que ahora a estos chicos les cuesta pronunciar el mapuche.

Ciertos niños y niñas coincidieron en el rol determinante de los padres: "Y aparte si no sale de tus padres que te enseñen! Si no le interesa a los padres menos les va a interesar a los hijos!" (Rita, 13 años). Algunos vincularon el desgano de sus compañeros con su negación como mapuche, como apuntó Valeria (14 años):

Son todos mapuche, pero no reconocen... digamos que ellos no quieren reconocer que son mapuche. Por ejemplo tengo una compañera que dice que no, que ella no estudia mapuche porque su mamá no sabe, porque su papá no sabe y su abuela no era mapuche y su abuelo no era mapuche. O sea está ahí [en la clase], pero no lo da importancia, y no estudia tampoco, no hace nada, digamos, en [la clase de] mapuche.

La selección de contenidos anclada en el pasado, lejanos a la experiencia de los niños, fue identificada por algunos docentes mapuche como causa de dicha apatía. Así, Mirta, afirmó:

Si yo le empiezo a conversar a lo mejor alguna historia pasada, no tienen ni, ni la menor idea, viste? Me ha pasado a mí (...) En su forma de... eh...de vivienda por ejemplo. Es por eso, la mayoría de los chicos ya hoy tienen otro tipo de vivienda, cosa que eh, en la vivienda del pasado ya tampoco tenían conocimiento de cómo era su estructura (...).Y bueno, ahí, es donde yo te decía que por ahí se lo toman preguntándose para qué le va a servir, no?.

Ciertos niños y niñas adoptan una actitud no sólo indiferente sino renuente respecto de la lengua y cultura mapuche, particularmente quienes participan en alguna de las diversas iglesias evangélicas, de significativa y progresiva incidencia desde los años 1980 entre la población mapuche del centro y sur de Neuquén. Brevemente, algunas de estas iglesias suelen presentar al evangelismo, el catolicismo y la cultura mapuche como religiones diferentes, mutuamente excluyentes, rechazando particularmente el mapuzugun-calificado en ciertos casos de demoníaco- y prohibiendo su utilización dentro de las iglesias. No sorprende entonces que algunos padres y madres, integrantes de dichos cultos, hayan solicitado reiteradamente reunirse con las autoridades escolares para que sus hijos e hijas sean eximidos del PELCM. O que los propios niños y niñas evangélicos reconocieran abiertamente que "nunca voy a aprender" porque "no hago ese empeño de decirle a la maestra que me enseñe a decir alguna cosa y que me diga qué es lo que es" (Gisela, 11 años).

Se da también el caso de niños y niñas de familias con trayectoria de militancia político cultural mapuche, que rechazan el catolicismo, el evangelismo y el nacionalismo por considerarlos imposiciones, y sin embargo, tampoco se entusiasman por las clases del PELCM. Pues advierten en el programa una "contaminación" de la cultura mapuche con creencias de origen cristiano y con la simbología nacional y provincial. "Discutimos con 
la maestra mapuche porque sí, porque ella también habla de dios y todo eso y como yo no creo en dios.... y ella dice que sí, que existe, me entendés?" (Valeria 14 años). Las disputas por consagrar determinada definición de la identidad mapuche se realizan también cotidianamente en las aulas.

Es importante señalar que algunos de estos niños y niñas hacen suyos ciertos conocimientos transmitidos en el marco del PELCM, como por ejemplo Facundo (10 años), quien tomando una hoja de un árbol adjunto a su vivienda me explicó "esto se hace así, doblada así, y después lo podés poner como crema, así me dijo la maestra de mapuzugun, te la dejabas puesta una noche y te curás la, la cara, así". Nótese cómo él evita castellanizar el nombre de su lengua.

Así, con distintos matices, la población mapuche viene reclamando otro contenido para la EIB, como indica por ejemplo Marta, madre de cuatro niños/as alumnos/as del PELCM: "Enseñan palabras sueltas, los instrumentos, el kulxug (instrumento ritual de percusión). ¿Pero qué va a enseñar? Tendría que enseñar la historia, la naturaleza, el respeto que hay que tener con cada newen (fuerza de la naturaleza)". En esos términos, tanto adultos/as como niños/as se refirieron críticamente a la reducción de la cultura e idioma mapuche a la enseñanza de "palabras sueltas", demandando en cambio se transmitan a los niños y niñas conocimientos, pautas de comportamiento mapuche adecuado y en algunos casos también "la historia" de su persistente resistencia y de su sometimiento a partir de fines del siglo XIX. En el marco del PELCM estos contenidos fueron hasta muy recientemente desestimados como signo de una politización inadmisible (Briones, 1999), debido a la perspectiva folklorizante y "armonicista" en la cual, como veremos a continuación, se funda este programa.

\section{Lo mapuche en disputa}

La presentación en el ámbito escolar -al igual que en otros ámbitos estatales neuquinosde las tradiciones mapuche como elementos confinados a un pasado inconmensurablemente remoto fosiliza la cultura mapuche y deslegitima manifestaciones culturales contemporáneas (Chiodi, 1997), despertando como vimos rechazo y desinterés en los niños y niñas. A su vez, genera "confusiones" tales como que "los mapuche antes eran monos, todos llenos de pelos" (Esteban, 10 años) o que los mapuche coexistieron con dinosaurios (Matías y Jorge, 9 años).

Lo mapuche es proyectado hacia los márgenes remotos también a través de la difusión de imágenes que estereotipan lo indígena de acuerdo al prototipo popularizado por las clásicas películas norteamericanas del género western. Así, lo aprendido por estos niños y niñas a través de su experiencia y de las interpelaciones de su entorno familiar y comunitario se ve confrontado por las nociones exotizantes que permean en algunos casos la cotidianeidad y los materiales escolares, como planteó asimismo Rita (13 años): 
No dicen la verdad en los libros sobre los mapuche, que danzaban... que dan vueltas... Pero no es la verdad de lo que hacen acá [en la ceremonia de su comunidad]. Le mostré ese libro de Billiken a mi tío [autoridad ritual] y me dijo que nos tratan de locos acá, y nada que ver. Y los maestros se llevan por lo que dice en los libros, nada más.

La reducción de la cultura mapuche al pasado pre-hispánico, al área rural y al ámbito de la tradición contribuye a neutralizar su conflictividad, fortaleciendo en cambio una perspectiva "armonicista", que confluye con el estilo local de construcción de hegemonía en el Neuquén, eludiendo "cuestiones cruciales ligadas a la opresión -el colonialismo, la desigualdad socioeconómica y el racismo" (Hermes, 2005, p.44). Como ha señalado Novaro, "la historia transcurre a partir de la negación de las desigualdades, los enemigos y los conflictos (...)" (2003, p.3), de acuerdo con el aún vigente "positivismo", que -como apuntó Batallán- presenta "un modelo de sociedad que la homologa a un organismo biológico (...) y los intentos de modificación pueden producir la inestabilidad del organismo social, atentando contra su salud" (1988, p.24).

El esfuerzo por transmitir a los niños y niñas mapuche esta visión armónica tan cara a la "neuquinidad" quedó de manifiesto en una actividad muy publicitada de la DPEIM. Se trata de la traducción de las estrofas del himno provincial al mapuzugun, realizada por los asesores del "consejo de ancianos" y los/as maestros/as mapuche, su posterior interpretación en diversos actos oficiales por un coro integrado por docentes mapuche y su informal instauración como contenido fundamental para los niños y niñas de las comunidades.

La centralidad asignada a este contenido evidencia el compromiso del programa con la economía política de producción de diversidad imperante en Neuquén (Briones, 2005), que a la vez que reconoce una cierta validez a la adscripción mapuche, la subordina a la pertenencia provincial. Esta primacía de "lo provincial" y los sesgos, que lejos de acercar a los niños y niñas a la cultura mapuche probablemente los distancien, nos llevan a plantear que nos encontramos frente a un discurso provincialista escolar, con significativos puntos en común con el discurso nacionalista escolar estudiado en Novaro (2003). La continuidad con las políticas educativas asimilacionistas y su resultante subordinación fue expuesta crudamente por Antonio, maestro mapuche que se negó a integrar el mencionado coro, quien atribuyó al PELCM el propósito de "seguir colonizando a los niños, con el nacionalismo, usando el mapuzugun".

La perspectiva a-conflictiva trasmitida a los niños y niñas se extiende asimismo a las relaciones entre el pueblo mapuche y el histórico accionar de la iglesia católica. A pesar del carácter oficialmente laico de la educación pública en la Argentina, en las escuelas públicas rurales no es sólo una excepción la enseñanza religiosa católica, a través de clases de catequesis dictadas después de hora, la instauración uniforme de prácticas cotidianas como la bendición de la mesa antes del almuerzo, o la periódica realización en el predio escolar de actividades misionales por parte de alumnos/as de escuelas medias católicas. Tal armonía -que se evidencia poéticamente en la letra del himno provincial ${ }^{8}$ - es políticamente reforzada por la DPEIM mediante la articulación promovida en la práctica con 
instituciones privadas tanto católicas como evangélicas. Aunque brevemente por razones de espacio, resulta relevante señalar que en la cotidianeidad escolar el PELCM transmite a los niños y niñas esa perspectiva sincrética, siendo en ciertos casos una de las primeras frases en mapuzugun a incorporar por parte de los niños y niñas: "Mañumain el que tev = Agradecer a Dios". (Cuaderno de clase de 3er grado)

De este modo, el PELCM interpela a los niños y niñas desde una confluencia entre "lo mapuche" -previamente fosilizado y despolitizado- y "lo católico" orientada en última instancia a hacer de ellos leales ciudadanos argentinos y sobre todo neuquinos. Consagrando determinados significados y valores que "en la medida en que son experimentados como prácticas parecen confirmarse recíprocamente” (Williams, 1997, p.131), el PELCM contribuye a la renovación de la hegemonía que en el Neuquén detenta esta particular articulación identitaria, compartida ampliamente por la iglesia católica y parte significativa de la población mapuche. Al mismo tiempo, el PELCM también torna visibles distintos modos en que dicha perspectiva hegemónica es cotidianamente desafiada. Entre las iniciativas contrahegemónicas sobresale el sentido de pertenencia propuesto por las organizaciones con filosofía y liderazgo mapuche (Briones, 1999), que impugna la ruralización de lo mapuche y las interpelaciones en términos provinciales, nacionales y religiosos (tanto católicos como evangélicos). Define en cambio la identidad mapuche en términos trasnacionales, asignando carácter diacrítico al conocimiento y práctica del mapuzugun, la "cosmovisión milenaria" y la "reivindicación de los derechos fundamentales" (Piciñan et. al., 2004, p.253), perfilando lo que en otra ocasión denominé definición contestataria de lo mapuche (Szulc, 2015a), que puede advertirse en parte significativa de los dichos y prácticas cotidianas de los niños/as y adultos/as mapuche frente al PELCM.

Estas contendientes construcciones de la identidad mapuche originan numerosas situaciones conflictivas entre adultos/as, entre niños/as y entre ambos conjuntos y el personal docente. Se han registrado casos en que los/as docentes reprenden a los niños y niñas por haberse ausentado para participar de una movilización en la ciudad capital de la provincia; casos de peleas entre niños/as católicos y evangélicos, o ni una cosa ni la otra; reclamos de los padres y madres a la escuela para que NO enseñen mapuzugun a sus hijos e hijas, o para que Sí lo enseñen pero contando "la verdadera historia"; también reclamos de los y las docentes no mapuche a los padres y madres por alumnos/as que se niegan a prometer lealtad a la bandera argentina, a vestir el guardapolvo blanco requerido a todo escolar argentino o a quitarse la gorra ante la bandera en el día a día escolar.

La niñez mapuche se evidencia entonces como un campo no meramente heterogéneo sino también disputado, conflictividad que se desarrolla siguiendo el estilo neuquino de construcción y disputa por la hegemonía, en lo cual intervienen múltiples agencias además de la familia y la escuela, a las cuales el sentido común suele restringir el accionar sobre la niñez. 


\section{Y sin embargo...}

En su primer encuentro, la maestra mapuche le propuso al grupo de niños y niñas de 4 años que se conozcan. Les preguntó “¿Cómo hacemos para conocernos?". A los chicos de los veía muy atentos, conectados con la propuesta. Fueron respondiendo "hablamos", "compartimos", "ayudamos”. “QQué les parece si nos conocemos jugando?", propuso la maestra mapuche, y tras la aceptación entusiasta de los niños y niñas, fue presentando uno a uno distintos instrumentos musicales mapuche, fue mostrando cada uno y contando y mostrando cómo suenan, cómo se llaman, nombrándolos en mapuzugun -sin castellanizar la pronunciación- insistiendo en que con ellos se expresa, se dice algo. Los chicos iban respondiendo y uno de ellos al escuchar el sonido del kulxug dijo "es como que se esparce". Y otro niño dijo que sentía el sonido en el corazón y la garganta. Ese niño también recordó que el año anterior el profe de música había llevado una pvfvlka y que les contó que para que suene mejor hay que echarle agua. La kvmeltuchefe luego fue repartiendo los instrumentos según las elecciones de los niños y niñas y guiando un ensamble. (Ciudad de Neuquén, 15 de mayo de 2017)

Más allá de la persistencia del diseño asimilacionista y apegado a la "lógica escolar", me parece relevante incorporar aquí un primer análisis de algunas experiencias que he registrado desde 2017, en las que desde dentro del propio PELCM se están produciendo sugerentes transformaciones.

Por un lado, como ya anticipé, resulta notable el que en 2017 se haya dado lugar al pedido de designación de una maestra mapuche y una suplente en la ciudad de Neuquén capital, para un jardín de infantes ubicado en un barrio con alta proporción de población mapuche de la zona oeste. En este caso fue de vital importancia el trabajo intercultural que parte del plantel docente venía realizando con educadoras mapuche, con aval de la dirección del jardín, a partir del cual el pedido se formuló desde la propia institución. Como lo expresó una de las docentes del jardín frente a todo el equipo y a las familias en ocasión del inicio de día lectivo: "es una gran alegría que se incorporen las maestras mapuche, y es parte de un proyecto institucional que comenzó hace varios años y que avanzó mucho el año pasado", que "van a comenzar por suerte en la sala azul, pero luego va a ir ampliando el trabajo a todas las salas" (17 de mayo de 2017).

Nos parece relevante destacar que las personas designadas en este jardín son jóvenes menores de 30, con formación terciaria y universitaria en curso, que en sus intervenciones en las aulas les vienen proponiendo a niños y niñas una aproximación a la lengua y la cultura mapuche a través del desarrollo de experiencias formativas en las que hacen mucho énfasis en lo vivencial, como puede observarse en la situación descrita, y que promueven sostenidamente el autoreconocimiento de niños y niñas como mapuche, a diferencia de las prácticas que anteriormente registramos que más bien resultaban desalentadoras, como ya se planteó. Por otro lado, en una comunidad rural del sur de la provincia he registrado interesantes cambios a partir del reemplazo generacional de la docente mapuche. La nueva maestra 
mapuche ronda también los 30 años de edad, y en sus clases pude observar cómo en el primer ciclo, además de hacerles escribir la fecha en mapuzugun, les propone a los niños y niñas juegos y canciones que cantan con mucho entusiasmo, involucrando movimientos corporales y recordando llamativamente la letra, a la vez que jugando para ir completándola de distintas formas. Resulta interesante cómo esta docente va buscando y reelaborando materiales para sus clases, a través de contactos personales con un "lamgen de Guluma$p u$ " (un hermano -no literalmente- de Chile), con educadoras de las organizaciones con filosofía y liderazgo mapuche y de su participación en ceremonias mapuche, además de en las contadas instancias de capacitación organizadas desde el PELCM.

Estas docentes que desde sus prácticas están transformando las experiencias formativas que en torno a la lengua y la cultura tienen algunos niños y niñas mapuche del Neuquén, son también el resultado del extenso y profundo trabajo educativo hacia adentro que desde hace décadas han venido desarrollando las organizaciones con filosofía y liderazgo mapuche, que -como analizamos en otra ocasión (Szulc, 2015b) han fortalecido las trayectorias escolares de niños, niñas y jóvenes mapuche desde una posición contestataria. Pues en efecto, a lo largo de más de dieciocho años de investigación en el Neuquén he registrado cómo estos niños y niñas, que cuestionan y desafían estereotipos que auguran su fracaso escolar, son precisamente quienes logran completar el ciclo primario, en ocasiones también el secundario, y acceder incluso al nivel superior. En estos distintos niveles, han ido asentando precedentes en las disputas identitarias, por ejemplo en el nivel primario y secundario, al ser designados para llevar la bandera nacional en los actos escolares de fin de año, lo cual suele ser un "premio" para los niños argentinos a su buen desempeño escolar o compañerismo. Sin embargo, los niños y niñas mapuche a los cuales nos hemos estado refiriendo han cuestionado que eso sea para ellos un reconocimiento, y propuesto y logrado en cambio portar en ya numerosas ceremonias escolares la bandera mapuche, wenu foye. ${ }^{9} \mathrm{O}$ bien, en el nivel universitario, en más de una ocasión jóvenes mapuche han recibido su título jurando ponerse al servicio de su pueblo, en lugar de los establecidos juramentos "por la patria" o "por los santos evangelios". No se trata simplemente de comportamientos de oposición, sino efectivamente de prácticas de resistencia, realmente "ligados a la indignación política o moral, y no sólo a la desviación o la impotencia aprendida" (Giroux, 1983, p. 289). Considero que es la inserción como maestros/as mapuche de esta nueva generación, formada de esta particular forma, lo que está generando estos incipientes cambios en el PELCM.

\section{A modo de cierre y apertura}

El análisis del programa de EIB neuquino ha tenido como propósito aportar a la reflexión sobre el diseño e implementación de políticas educativas interculturales en varios sentidos, desde una perspectiva antropológica. En primer lugar, queda claro que este tipo de programas oficiales deben comprenderse en el marco de la política indigenista del país y la provincia en la que se desarrollan, considerando el carácter descentralizado de la política educativa señalado por Peschel-Paetzold (2008). En nuestro caso, el PELCM claramente se 
entronca con la histórica tendencia nacional de "dar respuestas puntuales a casos puntuales' (...) desde los momentos claves de consolidación del estado argentino" (Briones, 2005, p.36) y, a nivel local, con el estilo fuertemente asistencialista, paternalista y clientelar de la política indigenista neuquina (Falaschi, Sanchez y Szulc, 2005). Asimismo, el diseño y sobretodo la implementación del PELCM revelan acciones basadas en el sentido de pertenencia provincial hegemónico, que a su vez lo refuerzan. Como se detalló, tras fosilizar la cultura mapuche y confinarla al ámbito rural, el PELCM la incorpora en términos subordinados, integrándola a sus redoblados esfuerzos por formar a los niños y niñas mapuche como fieles neuquinos, argentinos y buenos cristianos.

A su vez, el PELCM se inscribe en las tendencias de descentralización, segmentación y focalización de las políticas sociales que han caracterizado a las transformaciones del neoliberalismo conservador (Grassi, Hintze y Neufeld, 1994). Al circunscribirse casi por completo al ámbito rural comunitario, en lugar de orientarse a interculturalizar a los sectores hegemónicos (López, 2006), este programa no se distancia de los estereotipos que asimilan la diversidad cultural con una desventaja, estereotipos que se supone removería la interculturalidad (Bordegaray y Novaro, 2004). A pesar de enunciarse como promotor de la igualdad de oportunidades, el PELCM no basta para mejorar las trayectorias educativas de los niños y niñas mapuche, menos aún para revertir la segmentación del sistema educativo en escuelas profundamente desiguales.

En segundo lugar, el hecho de que el mapuzugun ocupe en la práctica del PELCM un lugar secundario, encuadrado por la desmarcada lengua dominante, refuerza la desigual relación de poder vigente entre las lenguas y sus hablantes, como han señalado Meek y Messing (2007), interrumpiendo el intento de revalorización enunciado en el diseño de este programa. De este modo, el paso de la lengua y cultura mapuche por el tamiz escolar no constituye, como advierte Novaro, meramente una "modificación' de los contenidos (como atributo posiblemente necesario, tratándose de alumnos pequeños)" sino una "distorsión, no didáctica sino ideológica (...) del sentido de los saberes" (2003, p.13).

En tercer lugar, este caso también evidencia el carácter disputado de los procesos de construcción y articulación de sentidos de pertenencia, con los que se entrama el PELCM. No se trata de la imposición en bloque de una cosmovisión prefabricada, cerrada y coherente, por parte de una clase dominante, sino de procesos en los cuales la población mapuche -familiares, alumnos/as, maestros/as y funcionarios/as- participa activamente, ya sea avalando ya sea impugnando los sentidos hegemónicos y disputándolos crecientemente desde dentro del propio programa.

En este sentido, en cuarto lugar, el análisis del PELCM y de las respuestas de los niños, niñas y adultos/as mapuche, ha evidenciado los complejos y conflictivos modos en que a través de los conflictos, resistencias y apropiaciones una política educativa parece estar siendo transformada, al menos incipientemente. No tanto por cambios en el abordaje educativo oficial de la "diversidad", sino más bien como fruto de un cambio en las estrategias de la población mapuche dentro y fuera del espacio escolar y de la renovación generacional de maestros y maestras.

Continuaré atendiendo a estas iniciativas, que en lugar de reproducir prácticas ancladas en la "lógica escolar" que deslegitiman la pertenencia mapuche y generan desinterés en 
los niños y niñas, están explorando estrategias vivenciales con las que estos/as docentes mismos se vienen formando en los proyectos de educación autónoma mapuche (Szulc, 2015b), promoviendo en el marco del propio PELCM el autoreconocimiento de los niños y niñas en tanto mapuche. Así, lo que anteriormente parecía un profundo desencuentro entre el diseño e implementación de este programa de EIB y el proyecto educativo de las organizaciones con filosofía y liderazgo mapuche (Szulc, 2009), viene -en algunos interesantes casos- reconfigurándose desde abajo, potenciando los esfuerzos de estos maestros y maestras, que ya no parecen estar tan solos.

\section{Notas:}

1. Para los términos en mapuzugun empleo el grafemario Ragileo, consensuado por diversas organizaciones mapuche del Neuquén, y letra cursiva, excepto puntualmente para el vocablo "mapuche", cuya grafía en Ragileo sería "mapuce", y al reproducir lo escrito según otro sistema en las clases del PELCM. Asimismo utilizo el término "mapuche" sin castellanizarlo, es decir, sin agregar una "s" en el plural de la palabra.

2. Actualmente el pueblo mapuche se asienta principalmente en las provincias de La Pampa, Buenos Aires, Neuquén, Río Negro, Chubut y Santa Cruz - en Argentina- y en Arauco, Bio-Bio, Malleco, Cautin, Valdivia, Osorno y Chiloe, en Chile, con una importante proporción de población dispersa en zonas rurales no reconocidas como comunidad mapuche (Carrasco y Briones, 1996) y más del 70\% asentada en centros urbanos según estimaciones del Instituto Nacional de Estadística y Censos. La migración de los jóvenes mapuche de las comunidades rurales a las ciudades es un fenómeno constante e históricamente profundo, a ambos márgenes de la cordillera de los Andes (Radovich y Balazote, 1992; Aravena, 2002).

3. La puesta en práctica del PELCM se registró en comunidades rurales ubicadas en los departamentos de Huiliches y Lacar, y a partir de 2017, en la ciudad de Neuquén, materiales que analizo aquí junto con entrevistas realizadas con maestros/as, funcionarios/as mapuche e integrantes de organizaciones mapuche en las ciudades de Neuquén, Junín de los Andes y Zapala.

4. En el año 1994, por medio del Artículo 75 inciso 17 por primera vez se reconocen en la Constitución Nacional los derechos de las comunidades indígenas de Argentina. El derecho a la EIB también es reconocido en la Ley Nacional $N^{\circ} 23.302$, la Ley Federal de Educación y la Resolución 107/99 del Consejo Federal de Cultura y Educación. En junio de 2004 se creó dentro del Ministerio Nacional de Educación el Programa Nacional de EIB.

5. Mientras en la provincia del Chaco -a pesar de las profundas contradicciones en cuanto al reconocimiento de otros derechos indígenas- se han oficializado las lenguas indígenas y se ha avanzado en la formación docente indígena desde 1987, en la creación de escuelas públicas de gestión social indígena y en la expansión de la EIB a los diferentes niveles educativos, en otras provincias el proceso de institucionalización de la EIB es mucho más reciente y limitado (Hecht et al 2018). 
6. En 2019 se registró que 9 de cada 10 niños, niñas y adolescentes indígenas no reciben clases en su lengua (González, 2019). Esto se agudizó por la decisión tomada por el Estado Nacional en febrero de 2017, de eliminar del organigrama del Ministerio de Educación la coordinación de la Modalidad de Educación Intercultural Bilingüe a nivel nacional -que hasta entonces diseñaba y llevaba a cabo capacitaciones docentes y producía materiales educativos en lenguas indígenas- diezmar su personal, reducir y subejecutar sustancialmente su presupuesto, y no convocar desde entonces al Consejo Educativo Autónomo de Pueblos Indígenas a nivel nacional (CEAPI).

7. La falta de respuestas a las demandas comunitarias ha dado lugar en ocasiones a "huelgas de alumnos" (Hecht y Szulc, 2006), que consiste en la inasistencia generalizada durante períodos prolongados, lo que puede dar lugar a modificaciones en las actitudes del personal o bien -mediante la visibilización en los medios masivos de comunicación- la intervención del gobierno provincial y el reemplazo de las autoridades del establecimiento. 8. Por ejemplo, una de las estrofas del himno neuquino expresa: "Un presagio de machi/ le corre por la sangre/ multiplicando panes/ igual que el nguenechen”. Además de la evidente intertextualidad con el texto bíblico -cuando se refiere a la "multiplicación de los panes"téngase en cuenta que Genecen (nguenechen) es un vocablo que designa en el idioma mapuche a una divinidad suprema, inculturación de la noción cristiana introducida por los misioneros jesuitas de la época colonial (Nicoletti 1995:14).

9. http://www1.rionegro.com.ar/arch200012/s18s12.html con acceso 30-01-15.

\section{Referencias Bibliográficas}

Aravena, A. (2003). Los mapuche-warriache. Procesos migratorios e identidad mapuche urbana. América indígena, LIX (4), pp. 162-188.

Batallán, G. (1988). El niño y el conocimiento de la realidad social en la escuela. En Elichiry, N. (Comp.) El niño y la escuela. Reflexiones sobre lo obvio. Buenos Aires, Argentina: Ediciones Nueva Visión.

Batallán, G. y M. R. Neufeld. (1988). Problemas de la antropología y la investigación educacional en América Latina. Cuadernos de Antropología Social 1 (2), Facultad de Filosofía y Letras, UBA, pp. 1-6.

Bordegaray, D. y G. Novaro. (2004). Diversidad y desigualdad en las políticas de Estado: Reflexiones a propósito del proyecto de Educación Intercultural Bilingüe en el Ministerio de Educación. Cuadernos de Antropología Social 19, pp. 101-119.

Briones, C. (1999). Weaving "the Mapuche People": the Cultural Politics of Organizations with Indigenous Philosophy and Leadership. Ph.D. Dissertation, University of Texas at Austin. Ann Arbor, Michigan, EEUU: University Microfilms International.

(2004). Del dicho al hecho. Poniendo la interculturalidad en sus varios contextos. En R. Díaz y G. Alonso (coords.) Construcción de espacios interculturales (pp.105-136). Buenos Aires, Argentina: Miño y Dávila. 
(2005). Formaciones de alteridad: contextos globales, procesos nacionales y provinciales. En Claudia Briones (ed.) Cartografías Argentinas. Políticas indigenistas y formaciones provinciales de alteridad (pp.11-43). Buenos Aires, Argentina: Antropofagia.

Briones, C. y R. Díaz. (2000). La nacionalización/ provincialización del "desierto". Procesos de fijación de fronteras y de constitución de "otros internos" en el Neuquén. En Actas del $V$ Congreso Argentino de Antropología Social, Parte III, pp. 44-57. La Plata, Argentina: Entrecomillas impresores.

Brow, J. (1990). Notes on Community, Hegemony, and the Uses of the Past. Anthropological Quarterly, 63, pp. 1-6.

Carrasco, M. y C. Briones. (1996). La tierra que nos quitaron. Documento IWGIA No 18. Buenos Aires, Argentina: IWGIA.

COM (Coordinación de Organizaciones Mapuche). (2000). Proyecto de Educación Intercultural, Neuquén, Octubre m.i.

Chiodi, F. (1997). Alcances de la noción de interculturalidad en educación. Clase inaugural de la Escuela de Antropología de la Universidad Academia del Humanismo Cristiano, Santiago de Chile, m.i.

Davini, M. C. (1995). La formación docente en cuestión: política y pedagogía. Buenos Aires, Argentina: Paidós.

Díaz, R. (2001). Trabajo docente y diferencia cultural. Lecturas antropológicas para una identidad desafiada. Buenos Aires, Argentina: Miño y Dávila.

Falaschi, C., F. Sánchez y A. Szulc. (2005). Políticas indigenistas en Neuquén: pasado y presente. En Claudia Briones (ed.) Cartografías Argentinas. Políticas indigenistas y formaciones provinciales de alteridad (179-221). Buenos Aires, Argentina: Antropofagia.

Fishman, J. (1991). Reversing language shift: Theoretical and empirical foundations of assistance to threatened languages. Clevedon, UK: Multilingual Matters.

Franzé, A. (2008). A la sombra del origen: lengua, cultura e identidad en los fundamentos de la ELCO. En M. I. Jociles Rubio y A. Franzé Mudanó (eds.) ¿Es la escuela el problema? Perspectivas socio-antropológicas de etnografía y educación (pp. 260-274). Madrid, España: Trotta.

Giroux, H. (1985). Teorías de la reproducción y la resistencia en la nueva sociología de la educación: un análisis crítico. Cuadernos Políticos, 44, pp. 33-65.

Godenzzi, J. C. (1997). Equidad en la diversidad. Reflexiones sobre educación e interculturalidad en los Andes y la Amazonía. En Godenzzi, J. C. y J. C. Pérez (comps.) Multilingüismo y educación bilingüe en América y España (pp. 19-30). Cusco: CBC.

Golluscio, L. (2002). From secrecy to public performance: the political uses of Mapuzungun. En C. Briones y J. L. Lanata (eds.) Contemporary Perspectives on the native peoples of Pampa, Patagonia and Tierra del Fuego. Living on the edge. (pp.149-163). CT: Bergin and Garvey's Co.

González, D. (2019). Estudiantes indígenas en escuelas argentinas. Una población invisibilizada. Datos de la Educación, año 2, $\mathrm{N}^{\circ}$ 4, Observatorio educativo de la UNIPE.

Grassi, E., S. Hintze y M. R. Neufeld. (1994). Políticas Sociales. Crisis y ajuste estructural. Buenos Aires, Argentina: Espacio Editorial.

Hall, S. (1986). Gramsci's relevance for the study of Race and Ethnicity. Journal of Communication Inquiry 10 (2), pp. 5-27. 
Hecht, A. C. (2004). Hacia una revisión de la categoría "niño" y “cultura wichí" a través de la escuela en el departamento Ramón Lista (Formosa). En Actas en CD VII Congreso Argentino de Antropología Social, Villa Giardino, Córdoba, 25 al 28 de mayo.

(2015). Educación intercultural bilingüe en argentina: Un panorama actual. Ciencia e interculturalidad, Año 8, 16 (1), pp. 20-30.

Hecht, A. C. y A. Szulc (2006). Los niños indígenas como destinatarios de proyectos educativos específicos en la Argentina, Qinasay. Revista de Educación Intercultural Bilingüe, año 4, No 4, Cochabamba, pp. 45-65.

Hermes, M. (2005). Ma'iingan is just a misspelling of the word wolf: A case for teaching culture through language. Anthropology \& Education Quarterly, 36 (2), pp. 43-56.

Hornberger, N. (1995). Escrituralidad, preservación de la lengua y derechos humanos lingüísticos: tres casos ilustrativos. Alteridades 5 (10), pp. 67-78.

Lanusse, P. (2004). La cuestión indígena en educación: algunas consideraciones acerca de la educación intercultural y bilingüe en el proyecto ANEPA. En: R. Díaz y G. Alonso (coords.) Construcción de espacios interculturales (pp. 137-150). Buenos Aires, Argentina: Miño y Dávila.

López, L. E. (2006). Desde arriba y desde abajo Visiones contrapuestas de la educación intercultural bilingüe en América Latina. Qinasay. Revista de Educación Intercultural Bilingüe. Año 4. No 4, pp. 45-66.

Meek, B. y J. Messing. (2007). Framing Indigenous Languages as Secondary to Matrix Languages. Anthropology \& Education Quarterly, 38 (2), pp. 99-118.

Mombello, L. (2005). "La "mística neuquina”. Marcas y disputas de provincianía y alteridad en una provincia joven”. En C. Briones (ed.) Cartografías Argentinas: políticas indigenistas y formaciones provinciales de alteridad (pp. 151-178). Buenos Aires, Argentina: Antropofagia

Mouffe, Ch. (1988). Hegemony and New Political Subjects: toward a New Concept of Democracy. En C. Nelson y L. Grossberg (eds.) Marxism and the Interpretation of Culture. Urbana, EEUU: University of Illinois press.

Nicoletti, M. A. (1995). Misioneros salesianos e indígenas patagónicos: predicando entre mapuche y fueguinos. S/d.

Novaro, G. (2003). “'Indios', 'Aborígenes' y 'Pueblos Originarios'. Sobre el cambio de conceptos y la continuidad de las concepciones escolares”. Revista Educación, lenguaje y sociedad. Facultad de Ciencias Humanas. Universidad Nacional de La Pampa, 1 (1), pp. 199-219. (2004). Pueblos aborígenes y escuela. Avances y obstáculos en el desarrollo de un enfoque intercultural. En Sistematización de Experiencias en Educación Intercultural y Bilingüe en Argentina. Buenos Aires, Argentina: Ministerio de Educación, Ciencia y Tecnología.

Padawer, A. y N. Enriz. (2009). Experiencias formativas en la infancia rural mbyá-guaraní, Avá 15, pp. 315-332.

Peschel-Paetzold, J. (2008). El programa de maestros especiales de Cultura e Idioma Mapuche como puesta en práctica de la Educación Intercultural Bilingüe en la provincia del Neuquén (Argentina)", Indiana, 25, pp. 143-167.

Piciñan, M., N. Sánchez, R. Nahuel, K. Kalfinahuel, M. Paillalef y R. Ñanku. (2004). Fortalecimiento del sistema educativo Mapuche. En Sistematización de Experiencias en 
Educación Intercultural y Bilingüe en Argentina. Buenos Aires, Argentina: Ministerio de Educación, Ciencia y Tecnología.

Puiggrós, A. (1990). Sistema educativo. Estado y sociedad civil en la reestructuración del capitalismo dependiente. El caso argentino. Propuesta Educativa, No 2, Flacso, Argentina.

Radovich, J. C. y A. Balazote. (1992). La problemática indígena. Estudios antropológicos sobre pueblos indígenas de la Argentina. Buenos Aires, Argentina: Centro Editor de América Latina.

Rockwell, E. (1980). Antropología y Educación: problemas acerca del concepto de cultura, m.i. (1995). De huellas, bardas y veredas: una historia cotidiana en la escuela. En E. Rockwell (coord.) La escuela cotidiana (pp. 13-57). México: FCE.

Rockwell, E. y J. Ezpeleta. (1985). La escuela, relato de un proceso de construcción inconcluso. En F. Madeira y G. Namo de Mello (Coords.) Educação na América Latina, os modelos teóricos e a realidade social (pp. 151-172). Sao Paulo, Brasil: Cortez Editora.

Sánchez, F. (2004). El Internado para niños indígenas Ceferino Namuncurá. Un caso paradigmático de educación asimilacionista. En R. Díaz y G. Alonso (coords.) Construcción de espacios interculturales (pp.183-194). Buenos Aires, Argentina: Miño y Dávila.

Sherzer, J. (1981) [1977]. A discourse-centered approach to language and culture. American Anthropologist 89, pp. 295-309.

Szulc, A. (2004). "Mapuche se es también en la waria (ciudad)": disputas en torno a lo rural, lo urbano y lo indígena en la Argentina. Política y Sociedad, $N^{\circ} 41-43$, Universidad Complutense de Madrid, pp. 167-180.

(2009). Becoming Neuquino in Mapuzugun (Mapuche language): Teaching mapuche language and culture in the Province of Neuquén, Argentina. Anthropology And Education Quarterly, 40 (2), pp. 129-149.

(2011). Esas no son cosas de chicos. Disputas en torno a la niñez mapuche en el Neuquén, Argentina. En D. Poveda, A. Franzé y M. Isabel Jociles (coord.) Etnografías de la infancia: discursos, prácticas y campos de acción (pp. 77 a 107). Madrid, España: Editorial La Catarata.

(2015a). La niñez mapuche. Sentidos de pertenencia en tensión, Buenos Aires, Argentina: Biblos.

(2015b). Concepciones de niñez e identidad en las trayectorias escolares de niños mapuche del Neuquén. Revista Anthropologica 33, N³5. PUCP, Perú. Pp. 235-253.

Teobaldo, M. (2000). Sobre maestros y escuelas. Una mirada a la educación desde la historia. Neuquén 1884- 1957. Rosario, Argentina: Arcasur.

Williams, R. (1997) [1977]. Marxismo y literatura. Barcelona, España: Ediciones Península.

\begin{abstract}
The province of Neuquén has historically had a strong state presence in mapuche communities, mainly through the setup of elementary schools and basic health centers. In that context, the hegemonic definition of identity -which relegates mapuche culture and subordinates it to the provincial and catholic identity - is reinforced, as well as the school's
\end{abstract}


model of childhood. Anthropological research carried out since 2001 has been showing how some mapuche children, adolescents and adults many times question such conceptions.

After a brief description of the educational system in this region, this article explores the agreements and desagreements in the design and implementation of the current program of Educación Intercultural Bilingüe (EIB) of the province of Neuquén for Mapuche children, examining the guidelines of this provincial policy and the perspectives and practices of institutional, communitary and family agents, including children themselves. Considering mainly original ethnographic materials, the analysis reveals how in the years passed since the original design of the programme in 2001, a new generation of young mapuche teachers has started to work differently, promoting experience-based self-recognition activities, instead of the out of context and fossilized and depoliticized presentation of mapuche language and culture that we recorded in the first years.

Keywords: Indigenous Policy Design - Childhood - Mapuche identity - indigenous policy - school trajectories.

Resumo: A província de Neuquén é historicamente caracterizada por uma forte presença estatal nas comunidades mapuche, principalmente através do estabelecimento de escolas primárias e postos de saúde. Nessas escolas, meninos e meninas são fortemente interpelados a partir da definição de identidade hegemônica - que articula os pertencimentos provinciais, nacionais e católicos, subordinando a eles a identidade mapuche - e a partir de um modelo escolar de infância. A pesquisa antropológica realizada com os Mapuche desde 2001 também mostram como alguns meninos, meninas, adolescentes e adultos/as questionam abertamente tais concepções.

Este artigo explora - depois de uma breve descrição do sistema educacional da província - os encontros e desencontros no desenho e implementação de um Programa Provincial para o Ensino da Língua e Cultura Mapuche neste contexto, analisando as diretrizes desta política provincial e as perspectivas e práticas dos atores institucionais, comunitários, familiares e das próprias crianças. Baseada principalmente em materiais etnográficos originais, a análise revela como, no tempo transcorrido desde o lançamento do Programa em 2001, as novas gerações de jovens professores e professoras mapuche se posicionaram de maneira diferente, promovendo espaços experimentais de auto-reconhecimento, em vez da apresentação descontextualizada, fossilizada e despolitizada da língua e cultura mapuche que registramos em seus primeiros anos (Szulc 2009)

Palavras chave: Desenho de política indigenista - infância - identidade mapuche - trajetórias escolares.

[Las traducciones de los abstracts fueron supervisadas por el autor de cada artículo] 